\title{
Cardiopulmonary Resuscitation: Update, Controversies and New Advances
}

\author{
Alexandre C. Zago, Cristine E. Nunes, Viviane R. da Cunha, Euler Manenti, Luís Carlos Bodanese
}

\author{
Porto Alegre, RS - Brazil
}

\begin{abstract}
Cardiopulmonary arrest is a medical emergency in which the lapse of time between event onset and the initiation of measures of basic and advanced support, as well as the correct care based on specific protocols for each clinical situation, constitute decisive factors for a successful therapy.

Cardiopulmonary arrest care cannot be restricted to the hospital setting because of its fulminant nature. This necessitates the creation of new concepts, strategies and structures, such as the concept of life chain, cardiopulmonary resuscitation courses for professionals who work in emergency medical services, the automated external defibrillator, the implantable cardioverterdefibrillator, and mobile intensive care units, among others.
\end{abstract}

New concepts, strategies and structures motivated by new advances have also modified the treatment and improved the results of cardiopulmonary resuscitation in the hospital setting. Among them, we can cite the concept of cerebral resuscitation, the application of the life chain, the creation of the universal life support algorithm, the adjust-ment of drug doses, new techniques-measure of the end-tidal carbon dioxide levels and of the coronary perfusion pressure - and new drugs under research.

Cardiopulmonary resuscitation (CPR) was developed in a model similar to the current basic life support (BLS), in 1865 , by a young medical officer of the U.S. Army - Charles Augustus Leale - but the reports about resuscitation measures date back to Biblical times. Since then, studies about the improvement of the method have been carried out and, in 1948, a meeting about CPR was held by the National Academy of Sciences-National Research Council. Sporadic meetings for the discussion of new techniques were held until 1961, when the American Heart Association (AHA) created the Committee on Cardiopulmonary Resuscitation, which began to coordinate research, training programs and standardization of CPR throughout the world. In 1973, the American Heart Association and the National

Hospital São Lucas da Pontifícia Universidade Católica do Rio Grande do Sul Porto Alegre.

Comissão de Ressuscitação Cardiorrespiratória - Cerebral.

Mailing adress: Alexandre C. Zago - Rua Hilário Ribeiro, 144/201 - 90510-040 Porto Alegre, RS.
Academy of Sciences-National Research Council held a new meeting in which the first steps of cardiopulmonary arrest (CPA) management were standardized, creating the protocols, also known as guidelines ${ }^{1,2}$.

This article aims to examine the new concepts, physiological mechanisms and therapeutical measures involving cardiopulmonary resuscitation; to point out and discuss relevant controversies, based on available studies; and to analyze the new advances documented in experimental studies in humans and animals.

The last guideline published by the AHA in JAMA ${ }^{3}$ is the primary landmark of the aims cited above.

In 1992, the AHA and the American College of Cardio$\operatorname{logy}$ (ACC) established a classification of the therapeutical measures according to their relative values. These measures were slightly modified by the International Liaison Committee on Resuscitation (ILCOR), created in 1992 and composed of organizations from several countries, aiming to bring the CPR measures into uniformity throughout the world ${ }^{3,4}$. The new classification will be used in this article to grade the usefulness of the therapeutical measures and is organized as follows: class I, definitely useful; class IIa, probably useful; class IIb, possibly useful; class III, inconclusive, possibly harmful.

The recently created concept of life chain is defined by a set of subsequent and strongly interrelated measures that, once implemented, provide better results than CPR alone. The links of the life chain consist of the early recognition of the CPA, early beginning of the BLS, precocious defibrillation, when indicated, and precocious implementation of the advanced cardiac life support (ACLS). This concept was initially proposed for out-ofhospital care of CPA, but was later extended to in-hospital resuscitation ${ }^{5,6}$. In this study, each link of the life chain will be discussed in detail.

\section{Basic cardiopulmonary resuscitation (CPR)}

Basic CPR or BLS should be started right after any health care professional inside a hospital or any professionally qualified first aid person verifies the unconsciousness of the patient. These people should be properly trained to 
provide the first aid of life support, which aims to maintain adequate cerebral and heart oxygen supply until the installation of the ACLS and reversal of the cardiac arrhythmia causing CPA with electrical shocks, when indicated.

Basic CPR comprises not only the cardiopulmonary support measures because it begins with the verification of the unconsciousness of the patient. Once this is done, the next step is to activate the ACLS service; to put the patient in the correct position; to check the known ABCs of CPR: A (airway) - to clear airway; B (breathing) - to check breathing and the need for ventilation support; $\mathrm{C}$ (circulation) - to check the central pulse, if absent, begin circulatory support ${ }^{7}$; and, more recently, $\mathrm{D}$ (defibrillation) - used in cases of ventricular fibrillation(VF) and ventricular tachycardia(VT) without pulse. These four measures form the ABCDs of the BLS ${ }^{8}$.

Inclusion of defibrillation in the BLS and the activation of the ACLS (second step of the basic CPR measures) result from the observation that $80 \%$ to $90 \%$ of the cases of CPA have $\mathrm{VF}$ as the initial cardiac rhythm and its treatment requires either immediate or the most precocious possible defibrillation.

Precocious defibrillation in BLS can be performed either by means of a conventional defibrillator, which requires special training of the operator for recognition of cardiac arrhythmias, or by means of an automated external defibrillator, which has the ability to recognize cardiac arrhythmias. This allows its use by first aid personnel with a basic training level, which is discussed in detail in the section "Perspectives and New Advances". Defibrillation should be performed only in cases of VF or VT without pulse with up to three consecutive electrical shocks of progressively higher voltage. At this stage, BLS is completed and ACLS begins ${ }^{8}$.

In case of trauma or drowning affecting children or adults, in which pulmonary arrest precedes cardiac arrest and early ventilation is decisive for the prognosis, the basic measures of CPR should be established one minute before asking for advanced support. Recent data suggest that VF is a cardiac rhythm rarely found in individuals younger than 30 years, and, therefore, the same conduct described above should be followed for this age range, in the absence of clinical and circumstantial information ${ }^{9}$.

If more than one first aid person is available, the discussion about the activation of the ACLS is solved through the division of tasks: while one first aid person asks for the ACLS, the others begin the BLS.

In case of suspected cervical damage, the patient should be very carefully positioned. If in doubt, act as if there were cervical damage, i.e., hold the patient's neck and occipital region with your hands while the victim is being moved, thus avoiding medullar compression and its harmful consequences.

The ABCDs of CPR, when correctly performed, can provide through mouth-to-mouth ventilation air with $16 \%$ to $17 \%$ of oxygen, causing an alveolar tension of $80 \mathrm{mmHg}$. This is considered adequate for the victim, in opposition to the former conception that the air expired by the first aid person would be poor in oxygen. AMBU (airway manual breathing unit) connected to an oxygen source of 10 to $15 \mathrm{~L} /$ min allows the obtainment of inspiratory oxygen concentration of up to $90 \%$, when coupled with a facial mask, and up to $100 \%$, when coupled with a tracheal tube.

External cardiac massage by chest compression, performed according to the conventional orientation, produces systolic pressure (SP) of 60 to $80 \mathrm{mmHg}$ and diastolic pressure (DP) of 15 to $35 \mathrm{mmHg}$. The mean carotid pressure, however, rarely exceeds $40 \mathrm{mmHg}$. Cardiac output resulting from external chest compressions ranges from one forth to one third of the normal; additional studies are necessary for its better assessment ${ }^{7,10}$.

In experimental studies, external chest compression interposed with abdominal compression revealed increase in SP and DP in the aorta, of the coronary perfusional pressure (CPP) and of the venous return to the heart, resulting in the elevation of cardiac output. The success of $\mathrm{CPR}$, reported in a study in pigs, was encouraging ${ }^{11}$, but results of CPR studies in humans were inconclusive ${ }^{12,13}$.

External chest compression associated with simultaneous ventilation aims at an additional increase of the intrathoracic pressure and, therefore, of the carotid flow, when compared with isolated external chest compression. Experimental studies in animals showed an increase of the carotid flow with this technique. Clinical studies, however, showed unsatisfactory results ${ }^{12-15}$.

Need for ventilatory support during the initial phase of the CPR measures was recently questioned by an experimental study in pigs ${ }^{16}$, stimulated by previous studies in animals. The results obtained showed similarities between the groups - ventilatory + circulatory support and isolated circulatory support, both initiated 2 minutes after CPA - in regard to survival in 24 and 48 hours and to neurological prognosis. These results, however, should not be interpreted as definitive. They do not reduce the importance of ventilatory support in the context of cardiopulmonary resuscitation, but they emphasize the importance of the reestablishment of the coronary blood flow and of the cardiac output through the measures of circulatory support. Additional studies should be carried out to definitely clarify this question; data currently available, however, suggest that the use of isolated circulatory support is better than indifference, resulting either from ignorance of the BLS measures or from the resistance of the first aid personnel in performing mouth-to-mouth ventilation until the arrival of ACLS.

\section{Precordial thump}

Precordial thump has mechanical energy that is converted into a stimulus estimated between 1 to $10 \mathrm{~J}^{17}$, which can be strong enough to reverse a cardiac arrhythmia, such as VT without pulse in $11 \%$ to $25 \%$ of the cases and VF in approximately $2 \%{ }^{3,18}$. Precordial thump, however, can accelerate the VT or convert it into VF, asystolia or electromechanical dissociation, worsening the clinical conditions of the patient ${ }^{3,18}$. 
Precordial thump is considered a class I therapeutical measure by ILCOR in cardiac arrest assisted by cardiac monitoring in the cases of VF or VT without pulse, and is considered class IIb in nonassisted cardiac arrest, but the AHA considers the precordial thump an optional technique in the cardiac arrest assisted with available defibrillator and class IIlb when the defibrillator is not immediately available ${ }^{19}$.

\section{Defibrillation}

In the presence of VF or VT without pulse, defibrillation should be performed as soon as possible because this therapeutical measure proved to be the most effective treatment for reversing the cited arrhythmias.

The energy levels recommended establish $200 \mathrm{~J}$ for the first electric shock, 200 to $300 \mathrm{~J}$ for the second, and $360 \mathrm{~J}$ for the third and subsequent therapeutical electric shocks. In case the arrhythmia is arrested with an energy level inferior to $360 \mathrm{~J}$ during the sequence of determined shocks, the reappearance of the arrhythmia implies the use of the last charge of energy that caused its reversion ${ }^{3,5,19}$.

\section{Tracheal intubation}

Tracheal intubation is a considered class I therapeutical measure by the ILCOR and AHA. It should be emphasized, however, that its performance must strictly follow the order according to the algorithm determined by the arrhythmia ${ }^{3,19}$.

The fact of giving priority to this procedure instead of the therapeutical electric shock in cases of VF or VT without pulse is contraindicated because of the delay in the application of the electric shock and, consequently, the decrease in success due to evolution of the arrhythmia with time.

\section{Vias of drug infusion}

The establishment of a via of access for drug infusion - class I therapeutical measure according to ILCOR - and the administration of drugs constitute secondary measures ${ }^{3,19}$. Therefore they should only be performed after the onset of the basic maneuvers of resuscitation, the cardiac defibrillation, when indicated, and the adequate obtainment and handling of the patent airway, which are considered primary measures ${ }^{3}$. Even though playing a secondary role, medicinal therapy is quite important for the success of the treatment of patients in CPA.

There are four vias of access for drug administration: venous, tracheal, intracardiac, and intraosteal.

The venous via of access is the first choice and can be obtained by catheterization of a peripheral or central vein. The peripheral vein should be located preferably in the superior limbs and the medication infused in the form of bolus with subsequent injection of $20 \mathrm{ml}$ of fluids and elevation of the corresponding limb. The central vein catheterized can be either the internal jugular or subclavian vein and the infusion of additional fluid and postural maneuvers are not necessary. The venous access should be kept through the infusion of solutions - saline solution or Ringer's solution providing a flow not inferior to $10 \mathrm{ml} / \mathrm{min}^{20}$.

In emergencies, when the venous access is mandatory, a peripheral or central vein can be catheterized without observing the recommended techniques for asepsis. However, with clinical stabilization of the patient, this via should be replaced by another, and the new puncture should be made observing all the asepsis guidelines ${ }^{20}$.

The tracheal access via represents an alternative when the venous access is impossible. The dose of medication administered by tracheal via should be 2 to 2.5 times greater than the recommended intravenous dose and should also be diluted in $10 \mathrm{ml}$ of saline solution or distilled water. The use of a long catheter that surpasses the distal extremity of the tracheal tube is advisable, as are subsequent pulmonary insufflations to transform the solution into aerosol, making its absorption easier ${ }^{3}$.

The intracardiac access via is used almost exclusively in CPA with open chest (surgery), when the venous access is impossible, and the heart is easily accessible under direct sight $^{21,22}$.

The intraosteal access via is also an alternative via although restricted to children, preferably under six years of age ${ }^{3,20}$.

\section{Pharmacology}

Oxygen - Oxygen should be used as soon as possible in all patients in CPA, in its highest concentration, i.e., preferably $100 \%$ (class I). This way, the arterial tension of oxygen is increased and, consequently, also the hemoglobin saturation, improving tissular oxygenation in the presence of cardiac output ${ }^{3}$.

Fluids - Intravenous infusion of liquids is not recommended routinely in the management of ACLS, because it can reduce cerebral and coronary blood flow by hemodilution. In cases of CPA with volume depletion, however, fluids should be infused - crystalloid and colloidal solutions or blood -as needed ${ }^{3}$.

Adrenaline or epinephrine - It is indicated in all cases of CPA at the dose of $1 \mathrm{mg}$ (average of $0.014 \mathrm{mg} / \mathrm{kg}$ ) intravenously every 3 minutes (class I) ${ }^{3,19,23}$. The use of high doses $(0.2 \mathrm{mg} / \mathrm{kg})$ did not show benefits in relation to the conventional dose, in regard to return of the spontaneous circulation and postresuscitation survival ${ }^{24-27}$. However, higher doses $(0.1 \mathrm{mg} / \mathrm{kg})$ can be used in cases not responding to the conventional dose (class IIb) ${ }^{3}$. An alternative schema is the use of intravenous escalating doses of adrenaline, beginning with $1 \mathrm{mg}$ and increasing the dose every 3 minutes $(1 \mathrm{mg}, 3 \mathrm{mg}, 5 \mathrm{mg}$, etc) until completing the total of $0.2 \mathrm{mg} / \mathrm{kg}^{3,23}$. Using this therapeutical schema, elevated doses are avoided in patients who need low doses 
and, on the other hand, adequate doses can be used in the cases responding to high doses.

In a recent controlled study with placebo ${ }^{28}$, adrenaline in conventional and high doses did not show benefits in regard to the success of CPR measures when compared with placebo. A possible explanation could be the beta-adrenergic stimulus through the increase of myocardial oxygen consumption, with a consequent increase in lactate production and a decrease in the concentration of adenosine triphosphate (ATP) ${ }^{29}$. Additional studies, however, should be carried out to clarify this question.

Atropine - Atropine is recommended in cases of asystolia, electric activity without pulse and symptomatic sinus bradycardia (class I), and in atrioventricular block, when accompanied by low output or ventricular arrhythmia (class IIa). The initial dose for asystolia and electric activity without pulse is $1 \mathrm{mg}$ given intravenously, which can be repeated every 3 to 5 minutes in the absence of initial response. In symptomatic sinus bradycardia, the recommended initial dose is 0.5 to $1 \mathrm{mg}$ given intravenously, which can be repeated every 3 to 5 minutes until the total dose of $3 \mathrm{mg}(0.04 \mathrm{mg} / \mathrm{kg})$, with which the complete vagal blockade can be obtained. The possible parasympathomimetic and depressing effect on heart rate should be emphasized when it is administered in doses less than $0.5 \mathrm{mg}$, as well as the possibility of triggering tachy-arrhythmias and consequently increasing the myocardial oxygen demand, when used in the dose of complete vagal blockade. This suggests that this dose should be restricted to the cases of asystolia ${ }^{3}$.

Lidocaine - Lidocaine is indicated in the cases of VF and VT without pulse resistant to treatment with electric defibrillation and administration of adrenaline (class IIb). The initial recommended dose is 1 to $1.5 \mathrm{mg} / \mathrm{kg}$ in bolus, with additional doses, if necessary, of 0.5 to $1.5 \mathrm{mg} / \mathrm{kg}$ in bolus and administered every 5 to 10 minutes until the total dose of $3 \mathrm{mg} / \mathrm{kg}$. In refractory $\mathrm{VF}$, the recommended initial dose is $1.5 \mathrm{mg} / \mathrm{kg}$ in bolus, followed by $1.5 \mathrm{mg} / \mathrm{kg}$ in bolus every 3 to 5 minutes, totaling $3 \mathrm{mg} / \mathrm{kg}$. Once completed the maximum dose, additional doses of $0.5 \mathrm{mg} / \mathrm{kg}$ in bolus can be administered every 8 to 10 minutes, which should be respected because smaller intervals determine high potential of toxicity. After reversal of the cardiac arrest and reestablishing spontaneous blood circulation, a continuous infusion of 2 to $4 \mathrm{mg} / \mathrm{min}$ should be initiated preferably in cases of refractory VF. In patients with low cardiac output, older than 70 years and with impairment of the hepatic function, the dose should be reduced to half. After 24 hours of continuous infusion in any patient, the dose should also be reduced or the serum levels of the drug should be monitored ${ }^{3}$.

Procainamide - Procainamide is indicated in the treatment of recurrent VT and of the premature ventricular complexes, when the use of lidocaine is contraindicated or does not have satisfactory results (class IIb). The recom- mended dose is $20 \mathrm{mg} / \mathrm{min}$ until arrhythmia suppression is obtained, as well as arterial hypotension, enlargement of $50 \%$ of the QRS complex or total dose of $17 \mathrm{mg} / \mathrm{kg}$. In an emergency, a dose superior to $30 \mathrm{mg} / \mathrm{min}$ adding up to a total dose of $17 \mathrm{mg} / \mathrm{kg}$ can be used. The maintenance dose is 1 to $4 \mathrm{mg} / \mathrm{min}$, which should be reduced in the presence of renal failure ${ }^{3}$.

Bretylium - Bretylium is used in the treatment of persistent or recurrent VF without response to treatment with defibrillation, adrenaline and lidocaine; of VT with pulse that can not be controlled with lidocaine and procainamide; and of VT with enlarged complexes without response to lidocaine and adenosine. In VF, it is recommended at the dose of $5 \mathrm{mg} / \mathrm{kg}$ intravenously in bolus, followed by defibrillation in 30 to 60 seconds. In the absence of a satisfactory response, the dose can be increased to $10 \mathrm{mg} / \mathrm{kg}$ and repeated every 5 minutes until the maximum dose of 30 to $35 \mathrm{mg} / \mathrm{kg}$ has been administered. In recurrent VT, a dose of 5 to $10 \mathrm{mg} / \mathrm{kg}$ diluted in $50 \mathrm{ml}$ of $5 \%$ saline solution is used every 8 to 10 minutes, followed by a maintenance dose of 1 to $2 \mathrm{mg} / \mathrm{min}$ in continuous infusion ${ }^{3}$.

Calcium - Although an important element in cardiovascular physiology, calcium did not prove to have any beneficial effects in retrospective and prospective studies carried out in patients in CPA. Therefore, the use of calcium salts is only recommended in cases of hyperkalemia, hypocalcemia, and intoxication due to calcium channel blockers (class IIa) ${ }^{3,30}$.

Calcium should be administered in bolus of 2 to $4 \mathrm{mg} / \mathrm{kg}$ of a solution of $10 \%$ calcium chloride $(1.36 \mathrm{mEq} \mathrm{Ca} / 100 \mathrm{mg}$ of salt $/ \mathrm{mL}$ ) or 5 to $8 \mathrm{~mL}$ of $10 \%$ calcium gluconate $(0.46 \mathrm{mEq}$ $\mathrm{Ca}^{+2} / 100 \mathrm{mg}$ of salt $/ \mathrm{mL}$ ), repeated at intervals of 10 minutes, if necessary ${ }^{3,31}$.

Sodium bicarbonate - In 1962, sodium bicarbonate was incorporated into the routine pharmacological treatment measures for CPA, because of its benefits then suggested ${ }^{32}$. In further clinical and experimental studies, not only absence of the desired effects but also harmful effects with its use were evidenced, as well. Currently, it is known that sodium bicarbonate: 1) does not alter the success indices of defibrillation, restoration of spontaneous circulation and short-term survival; 2) does shift the curve of saturation of oxyhemoglobin, inhibiting the release of oxygen; 3 ) does induce hyperosmolarity and hypernatremia; 4) does cause paradoxical intracellular acidosis through the formation of carbon dioxide resulting from the splitting of the molecule of $\mathrm{NaHCO}_{3}$, which is easily diffused to the interior of the myocardial and cerebral cells, aggravating the already existing ischemic process; 5) does inactivate the catecholamines simultaneously administered; and 6) can cause extracellular alkalosis, making possible the appearance of refractory arrhythmias ${ }^{3}$.

Based on the considerations cited above, the indications for the use of sodium bicarbonate were reassessed 
and the drug has been restricted to the following situations: hyperkalemia (class I); preexisting metabolic acidosis and intoxication due to tricyclic antidepressant and phenobarbital (class IIa); and prolonged CPR (class IIb). Therefore, contrary to what was formerly believed, sodium bicarbonate should not be used in the hypoxic lactic acidosis (class III), where, in addition to being ineffective, it can also be harmful ${ }^{3}$.

The initial recommended dose of sodium bicarbonate is $1 \mathrm{mEq} / \mathrm{kg}$, followed by $0.5 \mathrm{mEq} / \mathrm{kg}$ every 10 minutes in the absence of analysis of blood gases ${ }^{3}$. When this analysis is available, however, the dose can be calculated according to the following formula ${ }^{33}$ :

$\mathrm{HCO}_{3}$ deficit $(\mathrm{mEq})=0.6 \mathrm{X}$ weight $(\mathrm{kg}) \mathrm{X}\left(\right.$ desired - measured $\left.\mathrm{HCO}_{3}\right)$

Note: If serum $\mathrm{HCO}_{3}$ is inferior to $10 \mathrm{mEq} / \mathrm{L}$, the constant 0.7 should be used instead of 0.6.

In order to reduce the risk of alkalosis induced by the administration of sodium bicarbonate, the complete correction of the base deficit should be avoided. However, some authors do not accept the isolated analysis of blood gases as representing the tissular perfusion in CPA. They suggest a more adequate evaluation with the interpretation of the mixed arterial and venous analysis of blood gases, arteriovenous difference of $\mathrm{pH}$ and of partial pressure of $\mathrm{CO}_{2}$, and capnography ${ }^{32,34-39}$.

As already cited, sodium bicarbonate remains an important drug for cerebral CPR. However, the significance of alveolar ventilation and blood circulation, when promptly and adequately installed, should be emphasized in the reestablishment of the acid-base balance, avoiding many times the use of alkaline solutions ${ }^{3,32,34,35}$.

Magnesium sulfate-Magnesium sulfate is indicated in cases of hypomagnesemia associated with VT or refractory or recurrent VF and also torsade de pointes (class IIb). The recommended dose is 1 to $2 \mathrm{~g}$ diluted in $100 \mathrm{ml}$ of $5 \%$ saline solution, administered in 1 to 2 minutes ${ }^{3}$.

\section{Cardiac pacemaker}

A cardiac pacemaker is indicated in the presence of dysfunction in the formation or conduction of the electric impulse, causing bradycardia with hemodynamic repercussion (systolic pressure $<80 \mathrm{mmHg}$, alteration of consciousness, myocardial ischemia and/or pulmonary edema), or supraventricular/ventricular tachyarrhythmias refractory to pharmacological treatment or electric cardioversion. Bradycardia with hemodynamic repercussion may originate from second and third degree atrioventricular blocks, bradycardia induced by drugs (digoxin, beta-blockers, calcium channel blockers, procainamide), idioventricular bradycardia, refractory bradycardia secondary to hypovolemic shock, and atrial fibrillation or flutter with a high degree of atrioventricular block ${ }^{3}$.
A cardiac pacemaker is not indicated for VF or VT, but can be used for the treatment of asystolia (class IIb) and electric activity without pulse, although generally ineffective. This occurs because these rhythms are usually triggered by prolonged myocardial hypoperfusion, showing, consequently, restricted myocardial response to electric stimulus. Therefore, the emergency pacemaker should be used as soon as possible in these cases, when indicated, for satisfactory results, because of their close relation with the period of myocardial ischemia ${ }^{3}$.

The main indication for the emergency cardiac pacemaker comprises the arrhythmias potentially causing CPA, acting, thus, as an important prophylactic and modest therapeutical measure.

There are two types of pacemakers that can be used in these cases: transthoracic and pervenous. The placement of the transthoracic pacemaker is simple because it does not require vascular puncture. This makes it the first choice in cases requiring immediate treatment and in patients receiving or who may receive thrombolytic agents. Analgesia with narcotics or sedation with benzodiazepine compounds are recommended because of the discomfort resulting from muscle contraction. The placement of the pervenous pacemaker requires puncture of a central vein for the introduction of an electrode that will be fixed to the right ventricle apex. The choice of the type of pacemaker depends on the situation. The transthoracic pacemaker may be temporarily used aiming at hemodynamic stabilization until the pervenous one can be placed ${ }^{3,22,40}$.

\section{Universal algorithm - ILCOR}

In 1992, the AHA published an extensive detailed and updated review on CPR, comprising nine algorithms for treatment of CPA and severe clinical situations that may lead to CPA.

In that same year (1992), ILCOR was formed, comprising the AHA, the European Resuscitation Council (ERC), the Heart and Stroke Foundation of Canada (HSFC), the Australian Resuscitation Council (ARC), the Resus-citation Councils of Southern Africa (RCSA) and the recent Council of Latin America for Resuscitation (CLAR), aiming at standardizing and spreading the scientific knowledge on $\mathrm{CPR}^{4}$.

In 1997, ILCOR published a universal algorithm to guide the treatment of different situations of CPA (fig. 1) ${ }^{19}$.

This algorithm is markedly simple resulting, therefore, in easy understanding, immediate acceptance, and practical management. On the other hand, the main negative point is superficiality, which restrains the isolated use of the algorithm for the treatment of CPA, because it does not provide medication doses and alternative therapeutical routes to increase the chances of success of the basic and advanced support measures. Another negative point is the lack of agreement among the ILCOR members in regard to effectiveness and indication of the precordial thump.

Considering the positive and negative points of the 


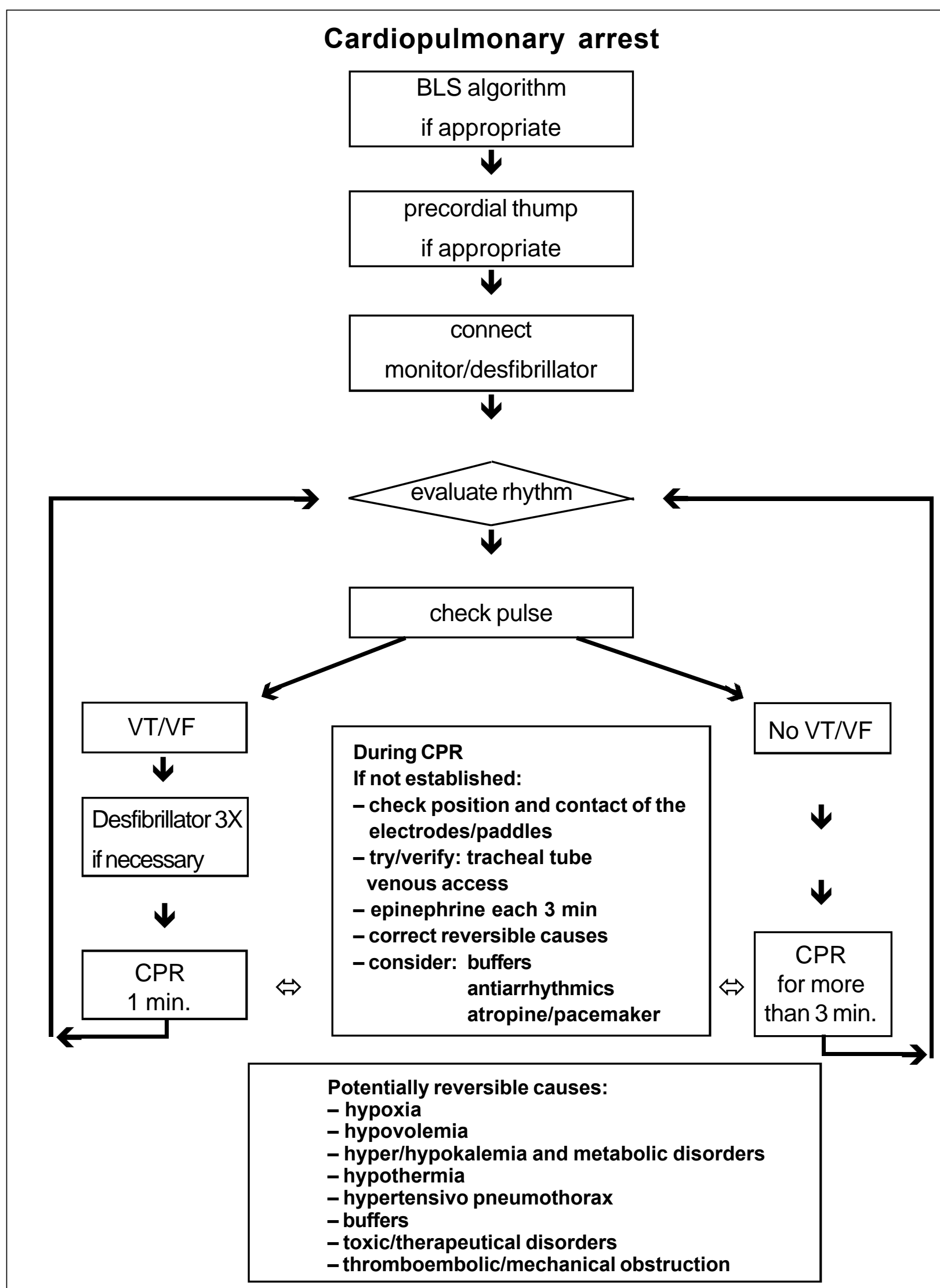

BLS = Basic Life Support; VT = Ventricular Tachycardia; VF = Ventricular Fibrillation; CPR = Cardiopulmonary Resuscitation. 
simplified algorithm, its use is justified in the orientation of CPR teams in regard to which steps to follow, along with the experience of the leading physician of the CPR team and the eventual alternative source of consultation.

\section{Cerebral resuscitation}

The brain is the most sensitive organ of the human body to fluctuations in the oxygen supply, because it uses only aerobic metabolism to obtain energy and it cannot store glucose and oxygen. Its oxygen and glucose contents are depleted in about 5 minutes of metabolism, with subsequent neuronal damage and death ${ }^{41,42}$.

Therefore, the central nervous system is currently receiving more attention in the context of CPR. The concept of cerebral resuscitation has arisen corresponding to the measures taken after the reestablishment of spontaneous circulation aiming to arrest or minimize the anoxic-ischemic cerebral lesion, directly related to the functional incapacity and poor prognosis following $\mathrm{CPR}^{41,42}$.

A neurological lesion is determined by tissular ischemia during the absence of blood flow and can be prolonged for hours or days after the reestablishment of the spontaneous circulation by the so-called postresuscitation cerebral syndrome, which occurs after 10 to 20 minutes of absence of spontaneous cerebral blood flow in normothermic conditions. This syndrome consists of four components: 1) failure of cerebral perfusion with decrease of oxygen supply to the brain; 2) cerebral reoxygenation, which causes damage through the activation of a cascade of chemical events, i.e., intracellular influx of calcium, tissular lactic acidosis and increase in the concentration of free fatty acids, free radicals and excitatory amino acids, such as glutamate and aspartate. This cascade has been documented in vitro and in extracerebral organs, but not yet in the brain in vivo; 3) extracerebral abnormalities, such as hyperthermia, hypoxemia, hypercapnia, disorders of the acid-base metabolism, renal and hepatic failure, and bacterial translocation from the intestinal wall impaired by ischemia; and 4) blood abnormalities secondary to stasis, such as aggregates of polymorphonuclear leukocytes and macrophages that can release free radicals, damage the vascular endothelium and obstruct blood capillaries resulting in microinfarctions ${ }^{41-44}$.

Based on the postresuscitation neuronal viability, i.e., the possibility of reversing the process of neurological lesions that spreads after the reestablishment of spontaneous cerebral circulation, and on the pathophysiological mechanisms of the postresuscitation neuronal lesion, therapeutical measures were established, consisting in the cerebral resuscitation presented below.

Cardiovascular measures - Among the cardiovascular measures, the increase of the perfusion pressure through the use of adrenaline during the CPR maneuvers, should be implemented as soon as possible. The administration of high doses of adrenaline during CPR is potentially beneficial to cerebral perfusion.
Another measure is the induction of hypertension in the phase of spontaneous cerebral reperfusion - SP between 150 and $200 \mathrm{mmHg}$ - during 1 to 5 minutes ${ }^{45-49}$, which can occur secondarily to the use of adrenaline during CPR or directly with the administration of noradrenaline with the reestablishment of the spontaneous circulation. Increased pressure levels in this phase are necessary to surpass the no-reflow phenomenon - multifocal and transitory absence of cerebral perfusion ${ }^{50,51}$ - and the increase of the intracranial pressure, which provides important resistance to blood flow. However, severe induced hypertension should not be prolonged, because of the secondary myocardial ischemia and the worsening of the cerebral vasogenic edema ${ }^{52,53}$.

Elevation of the head of the bed at $30^{\circ}$ facilitates cerebral venous drainage, reducing the intracranial pressure, which is usually increased 20 to 30 minutes after spontaneous circulation resumes. Knowing that the cerebral perfusion pressure is equivalent to the difference between the systemic mean blood pressure and the intracranial pressure, the use of the combination transitory hypertension and elevation of the head of the bed is justified and provides better results $3,22,41,45$.

After the period of transitory hypertension, normotension or mild hypertension are recommended, which can be attained with the infusion of fluids isolated or associated with dopamine, dobutamine and other drugs.

Hemodynamic monitoring with the Swan-Ganz catheter, when possible, is indicated for adequate hemodynamic management.

Pulmonary measures - Respiratory support can range from oxygen use through a nasal catheter to mechanical ventilation with intermittent positive pressure, depending on the level of consciousness and on the parameters of the blood gases.

In cases of coma following CPA, controlled mechanical ventilation for at least 12 hours is recommended to avoid cardiopulmonary failure in addition to providing oxygen during the period of the highest oxygen extraction, i.e., 2 to 12 hours after spontaneous cerebral reperfusion ${ }^{41}$. Positive end-expiratory pressure (PEEP) should be avoided or used in its lowest value possible in order to minimize the increase of the intrathoracic pressure, which causes reduction of the venous return to the heart.

Water and electrolyte measures - Blood volume, diuresis and electrolytes should be evaluated to keep serum osmolarity between 280 and $330 \mathrm{mOsm} / \mathrm{L}$ and normal levels of electrolytes, correcting electrolyte disorders and replacing fluids, whenever needed ${ }^{41}$. Infusion of dextrose (class III) should be avoided because of the potential risk of increasing the production of lactic acid, which promotes cellular damage ${ }^{3}$.

Hematological measures - Hematocrit levels should be kept between 30 and $35 \%{ }^{41}$. 
Metabolic measures - Hypo and hyperglycemia should be corrected to keep serum levels of glucose between 100 and $200 \mathrm{mg} / \mathrm{dL}^{41}$.

Normothermia must be maintained and convulsions controlled with phenobarbital, phenytoin or diazepam, because hyperthermia and convulsions increase oxygen consumption by the brain. Even mild hyperthermia should be corrected. Experimental studies in animals showed benefits with mild hypothermia $\left(34^{\circ} \mathrm{C}\right)$ that, in addition to exerting a cerebral protective effect, does not induce arrhythmia as occurs in moderate hypothermia $\left(30^{\circ} \mathrm{C}\right)$. Conclusive clinical studies in humans, however, are not available ${ }^{41}$.

Calcium channel blockers (nimodipine and lidoflazine), barbiturates, corticosteroids and anti-free radicals are being studied. The results obtained so far, however, do not show concrete benefits that justify their use in cerebral resuscitation ${ }^{41,42}$.

In regard to neurological prognosis, clinical studies proved it to be poor with rare cases of neurological recovery without functional incapacity after three days of coma. The results were even worse after seven days of coma; in this group, no case of neurological recovery without functional incapacity was evidenced. Analyzing patients in coma for 30 days, provided discouraging results, because there was no record that consciousness had been regained ${ }^{54,55}$.

These prognostic factors of neurological recovery only emphasize the importance of the adequate management of the patient in CPA and the adoption of measures of cerebral resuscitation, in order to avoid or minimize neuronal lesion, providing better neurological results.

\section{Ethical aspects. Identification of a final event and suspension of life support measures}

Measures of basic and advanced life support aim to prevent premature death with the reestablishment of the vital functions and of the functions of interpersonal and environmental relations. This does not imply prolonging the suffering of patients with end-stage chronic disease.

CPA can be subdivided into the potentially reversible and the irreversible. In the first situation, once the event is reversed, the patient regains conditions that allow the return to normal life if there are no neurological sequelae, or the patient can resume his/her normal activities with variable degrees of adaptation, depending on the resulting neurological damage. The second situation corresponds to the final event or death, in which the establishment of the measures of life support either does not reverse the cardiopulmonary collapse or enables only temporary success, because in a short period of time a new CPA will occur, determined by the base disease that cannot be treated or controlled, leading the patient invariably to death. In this last situation, the reversal of the CPA does not save a life but prolongs the patient's suffering; therefore, the use of CPR in patients with end-stage chronic diseases is not justified ${ }^{56}$.

Determining the adequate moment to suspend CPR measures, in the absence of reversion of the arrhythmia triggering the cardiopulmonary collapse, constitutes a difficult clinical decision, which, however, may be inevitable ${ }^{57}$. Aiming to help in this decision and based on clinical studies, four criteria were determined, which when fulfilled, allow the suspension of the life support measures: 1) CPA in adults not associated with trauma, hypothermia, drug intoxication and nonrespiratory etiology; 2) ACLS for more than 25 minutes; 3 ) failure in reestablishing spontaneous circulation, i.e., heart rate $>60 \mathrm{bpm}$ for at least 5 minutes; and 4) exclusion of refractory or recurrent VF/VT without pulse or of neurological activity (spontaneous respiration, eye opening or motor response) ${ }^{58}$.

\section{Perspectives and new advances}

Techniques - End-tidal carbon dioxide $\left(\mathrm{CO}_{2}\right)$ levels constitute an indirect measure of cardiac output during CPR. Several studies have shown its importance as a prognostic factor in patients in CPA with cardiac electrical activity without palpable arterial pulse ${ }^{59-62}$. The results obtained evidenced that end-tidal $\mathrm{CO}_{2}$ levels $\leq 10 \mathrm{mmHg}$ measured 20 minutes after ACLS onset are associated with a poor immediate prognosis, i.e., failure of the CPR measures in patients with cardiac electrical activity without palpable arterial pulse ${ }^{59,63-65}$. However, there was no correlation between the end-tidal $\mathrm{CO}_{2}$ levels measured before ACLS onset and immediate prognosis, as well as there was no correlation between the end-tidal $\mathrm{CO}_{2}$ levels and survival after the success of CPR ${ }^{9}$. Another important function of the end-tidal $\mathrm{CO}_{2}$ levels would be the documentation of the efficacy of the CPR measures, through the indirect measurement of cardiac output provided by therapeutical managements.

Coronary perfusional pressure (CPP) constitutes the pressure gradient between the aortic pressure and the right atrial pressure during the diastole of a normal cardiac cycle or during the relaxing phase in CPR. Experimental studies in animals and humans showed CPP's capacity as a prognostic factor in patients in CPA, especially after a long period of time, a situation for which data on humans are available ${ }^{66-71}$. Results of a study ${ }^{66}$ showed that initial CPP $<0 \mathrm{mmHg}$ and maximum CPP $<15 \mathrm{mmHg}$ are associated with absence of return to spontaneous circulation, but maximum $\mathrm{CPP}>15 \mathrm{mmHg}$ and $25 \mathrm{mmHg}$ is associated with $57 \%$ and $79 \%$ of return to spontaneous circulation, respectively. Another important function of CPP measure is monitoring in real time, which allows therapeutical decisions based on data obtained from the patient instead of decisions related to protocols of cardiac rhythms, such as currently occurs.

Drugs - Vasopressin or antidiuretic hormone (ADH) is produced by the posterior lobe of hypophysis (neurohypophysis) and released into blood flow in conditions of serum hyperosmolarity or depletion of extracellular volume. However, experimental studies in animals showed a potent effect of vasoconstriction even in the presence of hypoxia 
and acidosis, superior to and longer lasting than that of adrenaline. Therefore, vasopressin improves myocardial perfusion when compared with adrenaline ${ }^{72-74}$. Another important characteristic is that vasopressin does not increase myocardial consumption of oxygen $\left(\mathrm{MVO}_{2}\right)$ and, consequently, does not increase the production of lactate during CPA, unlike adrenaline ${ }^{72}$. Results of a study on humans showed higher efficiency of vasopressin at the initial dose of $40 \mathrm{U}$ in bolus than adrenaline at the conventional dose (protocol recommended by AHA) in the restoration of spontaneous circulation in patients with VF in severe hypoxemia and acidosis ${ }^{72}$. Angiotensin II is a nonadrenergic drug with a potent vasopressor action through the receptors of angiotensin. Experimental studies in animals showed its efficacy in increasing CPP, myocardial blood flow and myocardial oxygen supply $\left(\mathrm{MDO}_{2}\right)$ during CPR; however, there was also an increase in oxygen consumption $\left(\mathrm{MVO}_{2}\right)$. With the resumption of spontaneous circulation, myocardial blood flow and $\mathrm{MDO}_{2}$ and $\mathrm{MVO}_{2}$ remained elevated compared with the physiological parameters (preinduction of CPA). CPP, however, which had an improvement with angiotensin II during CPR, showed significant reduction compared with the physiological parameters ${ }^{75,76}$.

Endothelin-1, a peptide secreted by the endothelial cells, has a potent vasoconstrictive effect in vivo and in vitro, ten times stronger than angiotensin II and 1000 times stronger than noradrenaline. It acts through the nonadrenergic via, increasing the concentration of calcium in smooth muscle cells of the vascular wall ${ }^{77-79}$. It also has positive chronotropic and inotropic activities in heart models in vitro ${ }^{80-82}$. Results obtained in a study of dogs showed a significant increase in CPP with the use of endothelin-1 combined with the conventional dose of adrenaline. This was not observed with the isolated use of endothelin- 1 and adrenaline at the conventional dose ${ }^{77}$. Additional studies in animals, however, analyzing the different experimental models and additional clinical variables are necessary to justify clinical studies in humans.

Carbicarb $^{\circledR}$ is a buffer solution consisting of the mixture of sodium bicarbonate $\left(\mathrm{NaHCO}_{3}\right)$ and sodium carbonate $\left(\mathrm{Na}_{2} \mathrm{HCO}_{3}\right)$ in the concentration of 1:1. It has less bicarbonate, resulting in smaller formation of $\mathrm{CO}_{2}$ than sodium bicarbonate alone. This makes Carbicarb ${ }^{\circledR}$ a more effective buffer, according to results of experimental studies ${ }^{32,83-85}$.

Equipment - The automated external defibrillator has been gaining increasing importance with the inclusion of precocious defibrillation in basic CPR, due to its simplicity, accuracy, and safety, enabling its handling by first-aid personnel with limited training ${ }^{86}$. This increases the number of people capable of performing defibrillation, increasing the chances of precocious defibrillation and its significant benefits, as already discussed.

The automated external defibrillator is connected to the patient by two adhesive paddles - one at the right superior sternum border and the other upon the apex of the heart
- responsible for capturing and transmitting the cardiac rhythm from the patient to the device and for applying the electric shock. The fully automated defibrillator requires only placement of the adhesive paddles and pressing the button that starts the device. If the cardiac rhythm is VF or VT, the device automatically charges and applies the electric shock ${ }^{87}$. In the semiautomated or shock advisory defibrillator, the first aid person pushes the button "analyze" to analyze the cardiac rhythm and the button "shock" to apply the electric shock. Theoretically, the semiautomated defibrillator would be safer than the fully automated because in the first one the shock is applied at the moment the first aid person makes the determination. Clinical experience, however, shows that both are equally safe ${ }^{88}$.

The automated external defibrillator should be placed close to the left ear of the patient in a supine position, because of easy access to the controls and placement of the adhesive paddles. Furthermore, this position allows a second person to perform simultaneous basic CPR ${ }^{87}$.

The main difference between the automated and the conventional defibrillator is that the first one analyzes and interprets the cardiac rhythm, not requiring electrocardiographic knowledge from its operator.

This device is fundamental for mobile emergency services not constituted by physicians, because of easy training and maintenance, quick operation and cost viability. Other places that may require a defibrillator are medical offices, odontology clinics, maxillofacial surgical suites, or any place with high risk for sudden CPA. Places with difficult access are also potential candidates, such as aircrafts and long-distance ships for passenger transportation, and places with high concentrations of people ${ }^{86}$.

The implantable cardioverter-defibrillator is a small device with six basic components - one battery, one sensorial amplifier, one control circuit (microprocessor), one high voltage charger circuit, one capacitor for holding the power for defibrillation, and one high voltage circuit breaker capable of identifying potentially hazardous arrhythmias and automatically performing defibrillation or cardioversion ${ }^{89}$.

Indications for the use of this device were consensually established by ACC, AHA and the North American Society of Pacing and Electrophysiology in 1991, according to the following therapeutical classes: class I or acceptable: survival after cardiac arrest; VF or VT in patients whose electrophysiological test or Holter monitoring cannot be used as predictors of therapeutical efficacy; recurrent VF or VT despite pharmacological treatment guided by an electrophysiological test or Holter monitoring; VF or VT in patients in whom the medications are not tolerated or are inappropriate; and persistently inducible VF or VT despite adequate medicamentous treatment or ablation; class II or arbitrary: syncope of indefinite cause in patients with sustained VF or VT inducible in electrophysiological test; class III or usually not justified: VF or VT of irreversible cause (acute ischemia, recent acute myocardial infarction (AMI), toxic or metabolic disorders); recurrent syncope of indefinite cause and noninducible arrhythmia; incessant VF or VT; VF 
secondary to the syndrome of Wolf-Parkinson-White; and coexistent medical, surgical, or psychiatric contraindications ${ }^{89}$. After the Cardiac Arrhythmia Suppres-sion Trial (CAST) and Multicenter Automatic Defibrillator Implantation Trial (MADIT) studies ${ }^{90,91}$, the indications then restricted to secondary prevention were extended for use in primary prevention of cardiac arrest in patients with a history of AMI associated with left ventricular ejection fraction $\leq 35 \%$, documented episode of nonsustained VT and/or tachyarrhythmias inducible in electrophysiological testing.

The current devices have been programmed with predefined power of defibrillation between 18 and $25 \mathrm{~J}$, but there is not yet a consensus in regard to the determination of the value of the predefined power of defibrillation based on the threshold of defibrillation, i.e., the smallest power applied necessary to arrest the cardiac arrhythmia. However, recent data suggest that the severity of the left ventricular dysfunction and the use of some antiarrhythmic agents can increase the threshold of defibrillation to unacceptable values ${ }^{92}$.

In regard to efficacy, the Cardiac Arrest Study Hamburg (CASH) ${ }^{93}$ carried out in individuals surviving sudden cardiac arrest showed that the implantable cardioverter-defibrillator is superior to propafenone considering total mortality in one year and is associated with a significant reduction of two-year mortality, when compared with amiodarone and metoprolol, without any relevant difference between these two drugs (total mortality in two years: $12.1 \%$ and $19.6 \%$, respectively, with $\mathrm{p}=0.047$ ). The Canadian Implantable Defibrillator Study (CIDS) study ${ }^{94}$ compared the implantable cardioverter-defibrillator with amiodarone in patients surviving cardiac arrest or symptomatic sustained VF/VT and showed a modest, although not significant, reduction in total mortality in four years in the group of the implantable cardioverter-defibrillator (total mortality: $27 \%$ and $33 \%$, respectively, with $\mathrm{p}=0.07$ ). However, it should be observed that 30-day mortality was higher for the devices implanted with thoracotomy than for the nonthoracotomy lead system approach $(3.3 \%$ and $0.36 \%$, respectively).

Significant considerations about the implantable cardioverter-defibrillator should be emphasized. The first aid person in contact with the patient at the moment of the discharge can feel the shock, but it does not offer risks. The electrodes of the device usually cover a part of the epicardium surface, and can reduce the transcardiac current of the transthoracic shock. Therefore, if there is no success with the defibrillation with $360 \mathrm{~J}$, the position of the electrodes of the paddles of the external defibrillator should be changed to anteroposterior and the shock repeated. This change in position of the electrodes can increase the transcardiac current and, therefore, make the defibrillation easier ${ }^{87}$.

\section{Course on learning and systematization of CPA management}

The standardization of management of cerebral CPR developed by the AHA aims at providing complete assistance to patients based on state-of-the-art technology and evidence-based medicine, offering the best results possible. Therefore, the importance of the courses on learning and systematization of CPA management developed by the AHA should be emphasized, such as the courses on Basic Life Support (BLS), Advanced Cardiology Life Support (ACLS), and Pediatric Advanced Life Support (PALS).

\section{Acknowledgements}

The authors thank Dr. Timerman for his significant contribution.

\section{Referências}

1. Standards for cardiopulmonary resuscitation (CPR) and emergency cardiac care (ECC). JAMA 1974; 227: 833-68.

2. Bianchi e Silva CH, Mallmann Neto C. Reanimação Cardiorrespiratória Básica. In: Vieira SRR (coord.). Porto Alegre: Manual de Emergências Médicas: Editora. da Universidade/UFRGS, 1995: 15-43.

3. Adult Advanced Cardiac Life Support. JAMA 1992; 268: 2199-241.

4. Cummins RO, Chamberlain DA. Advisory Statements of the International L Committee on Resuscitation. Circulation 1997; 95: 2172-3.

5. Kloeck WK, Cummins RO, Chamberlain D, et al. Early Defibrillation. Circulation 1997; 95: 2183-4.

6. Cummins RO, Sanders A, Mancini E, Hazinski MF. In-Hospital Resuscitation. Circulation 1997; 95: 2211-2

7. Adult Basic Life Support. JAMA 1992; 268: 2184-98.

8. Advanced Cardiac Life Support. American Heart Association. 1997; 1: 1-77.

9. Handley AJ, Becker LB, Allen MA, et al. Single-rescuer adult basic life support. Circulation 1997; 95: 2174-9.

10. Paradis NA, Martin GB, Goetting MG, et al. Simultaneous aortic, jugular bulb, and right atrial pressures during cardiopulmonary resuscitation in humans. Circulation 1989; 80: 361-8.

11. Lindner KH, Ahnefeld FW, Bowdler IM. Cardiopulmonary resuscitation with interposed abdominal compression after asphyxial or fibrillatory cardiac arrest in pigs. Anesthesiology 1990; 72: 675-81.

12. American Heart Association. Adjuncts for artificial circulation. Textbook of Advanced Cardiac Life Support 1994; 11: 1-8.

13. Paiva EF. Equipamentos acessórios para controle da via aérea e técnicas especiais de ressuscitação cardiopulmonar. Rev Soc Cardiol Est SP 1997; 1: 33-41.

14. Chandra N, Weisfeldt ML, Tsitlik J, et al. Augmentation of carotid flow during cardiopulmonary resuscitation by ventilation at high airway pressure simultaneous with chest compression. Am J Cardiol 1981; 48: 1053-63.

15. Krischer JP, Fine EG, Weisfeldt ML, et al. Comparison of prehospital conventional and simultaneous compression-ventilation cardiopulmonary resuscitation. Crit Care Med 1989; 17: 1263-9.

16. Berg RA, Wilcoxson D, Hilwig RW, et al. The need for ventilatory support during bystander CPR. Ann Emerg Med 1995; 26: 342-50.

17. Pennington JE, Taylor J, Lown B. Chest thump for reverting ventricular tachycardia. N Engl J Med 1970; 283: 1192-5.

18. Kerber RE, Robertson CE. Transthoracic defibrillation. In: Paradis NA - Cardiac Arrest: the Science and Practice of Resuscitation Medicine. Baltimore: Williams \& Wilkins, 1996: 370-81

19. Kloeck WK, Cummins RO, Chamberlain D, et al. The universal advanced life support algorithm. Circulation 1997; 95: 2180-2. 
20. Stefanini E. Estabelecimento e manutenção das vias de infusão de medicamentos. Rev Soc Cardiol Est SP 1997; 1: 65-70.

21. Albarran-Sotelo R. Farmacologia. In: Lane JC, Albarran-Sotelo R (eds.) Reanimação Cardiorrespiratória Cerebral. Rio de Janeiro: Medsi, 1993: 247.

22. Zago AC, Verri JM. Reanimação cardiorrespiratória avançada. In: Vieira SRR (coord.) - Manual de Emergências Médicas. Porto Alegre: Editora da Universidade/UFRGS, 1995: 79-114.

23. Araújo S. Farmacologia no suporte avançado de vida. Rev Soc Cardiol Est SP 1997; 7: 71-8.

24. Ornato JP. Use of adrenergic agonists during CPR in adults. Part 2. Ann Emerg Med 1993; 22: 411-6.

25. Brown CG, Martin DR, Pepe PE, et al. A comparison of standard-dose and highdose epinephrine in cardiac arrest outside the hospital. N Engl J Med 1992; 327 : 1051-5.

26. Stiell IG, Hebert PC, Weitzman BN, et al. High-dose epinephrine in adult cardiac arrest. N Engl J Med 1992; 327: 1045-50.

27. Abramson NS, Safar P, Sutton-Tyrrell K, et al. A randomized clinical trial of escalating doses of high dose epinephrine during cardiac resuscitation. Crit Care Med 1995; 23: A178.

28. Woodhouse SP, Cox S, Boyd P, et al. High dose and standard dose adrenaline do not alter survival compared with placebo, in cardiac arrest. Resuscitation 1995; 20: $243-9$.

29. Ditchey RV, Lindenfeld J. Failure of epinephrine to improve the balance between myocardial oxygen supply and demand during closed chest resuscitation in dogs. Circulation 1988; 78: 382-9.

30. Thompson BM, Steuven HS, Tonsfeldt DJ, et al. Calcium: limited indications, some danger. Circulation 1986;74(suppl IV): IV90-IV3

31. Marino P - Calcium and phosphorus. In: Marino P - The ICU Book. Baltimore: Williams \& Wilkins, 1998: 673-88.

32. Máttar JA. Bicarbonato de sódio na parada cardiorrespiratória. Rev Soc Cardiol Est SP 1997; 7: 79-83.

33. Marino P. The organic acidoses. In: Marino P - The ICU Book. Baltimore: Williams \& Wilkins, 1998: 592-607.

34. Timerman A. Monitorização hemodinâmica e hemogasométrica na parada cardiorrespiratória. In: Terzi RGG, Araújo S (eds.) - Monitorização Hemodinâmica e Suporte Cardiocirculatório do Paciente Crítico. São Paulo: Atheneu, 1995: 269-77.

35. Máttar JA. Distúrbios ácido-básicos do adulto. In: Felix VN, Carvalho WB, Auler Jr JOC (eds.) - Terapia Intensiva Adulto. Pediatria/RN. São Paulo: Savier, 1997: 136-43.

36. Weil M, Rackow E, Trevino R, et al. Differences in acid-base state between venous and arterial blood during cardiopulmonary resuscitation. N Engl J Med 1986; 315: 153-6.

37. Gazmuri RJ, Von Plant M, Weil MH, et al. Arterial $\mathrm{PCO}_{2}$ as an indicator of systemic perfusion during cardiopulmonary resuscitation. Crit Care Med 1989; 17: 237.

38. Kette F, Weil MH, Von Plant M, et al. Buffer agents do not reverse intramyocardial acidosis during cardiac resuscitation. Circulation 1990; 81: 1660-6.

39. Weil MH, Grundler W, Yamaguchi M, et al. Arterial blood gases fail to reflect acid-base status during cardiopulmonary resuscitation: a preliminary report. Crit Care Med 1985; 13: 884-5.

40. Mateos JCP. Marcapasso externo - indicações e procedimentos básicos. Rev Soc Cardiol Est SP 1997;7:58-64.

41. Safar P. Cerebral resuscitation after cardiac arrest: research initiatives and future directions. (pt 2). Ann Emerg Med 1993; 22: 324-49.

42. Knobel E, Ferraz AC, Neto AC. Ressuscitação cerebral. Rev Soc Cardiol Est SP 1997; 7: 92-8.

43. Safar P. Cerebral resuscitation after cardiac arrest: A review. Circulation 1986; 74(suppl IV): IV138-IV53.

44. Kochanek PM, Hallenbeck JM. Polymorphonuclear leukocytes and monocytesmacrophages in the pathogenenesis of cerebral ischemia and stroke: A review. Stroke 1992; 23: 1367-75.

45. Canto R, Ames A, DiGancinto G, et al. Hypotension: A major factor limiting recovery from cerebral ischemia. J Surg Res 1969; 9: 525-9.

46. FischerEG, Ames A. Studies on mechanisms of impairment of cerebral circulation following ischemia. Effect of hemodilution and perfusion pressure. Stroke 1972; 3: $538-42$.

47. Harrison MJG, Sedal L, Arnold J, et al. No-reflow phenomenon in the cerebral circulation of the gerbil. J Neurol Neurosurg Psychiatry 1975; 38: 1190-3.

48. Hossmann KA, Lechtape-Gruter H, Hossmann V. The role of cerebral blood flow for the recovery of the brain after prolonged ischemia. J Neurol 1973; 204: 281-99.

49. Safar P, Stezoski W, Nemoto EM. Amelioration of brain damage after 12 minutes of cardiac arrest in dogs. Arch Neurol 1976; 33: 91-5.

50. Leonov Y, Sterz F, Safar P, et al. Hypertension with hemodilution prevents multifocal cerebral hypoperfusion after cardiac arrest in dogs. Stroke 1992; 23: 4553.
51. Sterz F, Leonov Y, Safar P, et al. Multifocal cerebral blood flow by Xe-CT and global cerebral metabolism after prolonged cardiac arrest in dogs. Reperfusion with openchest CPR or cardiopulmonary bypass. Resuscitation 1992; 24: 27-47.

52. Bleyaert AL, Sands PA, Safar P, et al. Augmentation of postischemic brain damage by severe intermittent hypertension. Crit Care Med 1980; 8: 41-7.

53. Klatzo I. Brain edema following brain ischemia and the influence of therapy. Br J Anaesth 1985; 57: 18-22.

54. Levy DE, Caronna JJ, Singer BH, et al. Predicting Outcome From HypoxicIschemic Coma. JAMA 1985; 253: 1420-6.

55. Bell JA, Hodgson HJF. Coma after cardiac arrest. Brain 1974; 97: 361-72.

56. Abdalla LA. Aspectos éticos e médico-legais da ressuscitação cardiopulmonar - ordens de não ressuscitar. Rev Soc Cardiol Est SP 1997;7: 175-82.

57. Kellermann AL, Hackman BB, Somes G. Predicting the outcome of unsuccessful prehospital advanced cardiac life support. JAMA 1993; 270: 1433-6.

58. Bonnin MJ, Pepe PE, Kimball KT, Clark OS. Distinct Criteria for Termination of Resuscitation in the Out-of-Hospital Setting. JAMA 1993; 270: 1457-62.

59. Levine RL, Wayne MA, Miller CC. End-Tidal Carbon Dioxide and Outcome of Out-of-Hospital Cardiac Arrest. N Engl J Med 1997; 337: 301-6.

60. Falk JL, Rackow EC, Weil MH. End-tidal carbon dioxide concentration during cardiopulmonary resuscitation. N Engl J Med 1988; 318: 607-11.

61. Asplin BR, White RD. Prognostic value of end-tidal carbon dioxide pressures during out-of-hospital cardiac arrest. Ann Emerg Med 1995; 25: 756-61.

62. Cantineau JP, Lambert Y, Merckx P, et al. End-tidal carbon dioxide during cardiopulmonary resuscitation in humans presenting mostly with asystole: a predictor of outcome. Crit Care Med 1996; 24: 791-6.

63. Sanders AB, Kern KB, Otto CW, et al. End-tidal carbon dioxide monitoring during cardiopulmonary resuscitation: a prognostic indicator for survival. JAMA 1989; 262: 1347-51.

64. Kern KB, Sanders AB, Raife J, et al. A study of chest compression rates during cardiopulmonary resuscitation in humans: the importance of rate-directed chest compressions. Arch Intern Med 1992; 152: 145-9.

65. Cantineau JP, Merckx P, Lambert Y, et al. Effect of epinephrine on end-tidal carbon dioxide pressure during prehospital cardiopulmonary resuscitation. Am J Emerg Med 1994; 12: 267-70.

66. Paradis NA, Martin GB, Rivers EP, et al. Coronary perfusion pressure and the return of spontaneous circulation in human cardiopulmonary resuscitation. JAMA 1990; 263: 1106-13.

67. Kern KB, Ewy GA, Voorhees WD, et al. Myocardial perfusion pressure: a predictor of 24-hour survival during prolonged cardiac arrest in dogs. Resuscitation 1988; 16: 241-50.

68. Redding JS, Pearson JW. Resuscitation from ventricular fibrillation. JAMA 1968; 203: 255-60

69. Sanders AB, Ewy GA, Taft TV. Prognostic and therapeutic importance of the aortic diastolic pressure in resuscitation from cardiac arrest. Crit Care Med 1984; 12: $871-3$

70. Niemann JT. Differences in cerebral and myocardial perfusion during closed-chest resuscitation. Ann Emerg Med 1984; 13: 849-53.

71. Niemann JT, Criley JM, Rosborough JP, et al. Predictive indices of successful cardiac resuscitation after prolonged arrest and experimental cardiopulmonary resuscitation. Ann Emerg Med 1985; 14: 521-8.

72. Lindner KH, Prengel AW, Brinkmann A, et al. Vasopressin Administration in Refractory Cardiac Arrest. Ann Intern Med 1996; 124: 1061-4.

73. Lindner KH, Brinkmann A, Pfenninger EG, et al. Effect of vasopressin on hemodynamic variables, organ blood flow, and acid-base status in a pig model of cardiopulmonary resuscitation. Anesth Analg 1993; 77: 427-35.

74. Lindner KH, Prengel AW, Pfenninger EG, et al. Vasopressin improves vital organ blood flow during closed-chest cardiopulmonary resuscitation in pigs. Circulation 1996; 91: 215-21.

75. Little CM, Brown CG. Angiotensin II improves myocardial blood flow in cardiac arrest. Resuscitation 1993; 26: 203-10.

76. Little CM, Hobson JL, Brown CG. Angiotensin II effects in a swine model of cardiac arrest. Ann Emerg Med 1993; 22 : 244-7.

77. DeBehnke DJ, Spreng D, Wickman LL, et al. The effects of endothelin-1 on coronary perfusion pressure during cardiopulmonary resuscitation in a canine model. Acad Emerg Med 1996; 3: 137-41.

78. Yanagisawa M, Kurihara H, Kimura S, et al. A novel potent vasoconstrictor peptide produced by vascular endothelial cells. Nature 1988; 332: 411-5.

79. Weitzberg E. Circulatory responses to endothelin-1 and nitric oxide with special reference to endotoxin shock and nitric oxide inhalation. Acta Physiol Scand 1993; 611:2-72.

80. Ishikawa T, Yanagisawa M, Kimura S, et al. Positive inotropic action of novel vasoconstrictor peptide endothelin on guinea pig atria. Am J Psysiol 1988; 255(suppl): H970-H3.

81. Moravec CS, Reynolds EE, Stewart RW, et al. Endothelin is a positive inotropic agent in human and rat heart in vitro. Biomed Biophys Res Commun 1989; 159: 14-8 
82. Ishikawa T, Yanagisawa M, Kimura S, et al. Positive chronotropic effects of endothelin, a novel endothelium derived vasoconstrictor peptide. Eur J Physiol 1988; 413: 108-10.

83. Bersin RM, Arieff AI. Improved hemodynamic function during hypoxia with Carbicarb $^{\oplus}$ : a new agent for the management of acidosis. Circulation 1988; 77 : 227-33.

84. Kucera R, Shapiro J, Whalen M, et al. Brain pH effects of $\mathrm{NaHCO}_{3}$ and Carbicarb in lactic acidosis. Crit Care Med 1989; 17: 1320-3.

85. Leung JM, Landow L, Franks M, et al. Safety and efficacy of intravenous Carbicarb in patients undergoing surgery: comparison with sodium bicarbonate in the treatment of mild metabolic acidosis. Crit Care Med 1994; 22: 1540-9.

86. Cummins RO. From concept to standard-of-care? review of the clinical experience with automated external defibrillators. Ann Emerg Med 1989; 18: 1269-75.

87. Advanced Cardiac Life Support. American Heart Association, 1997; 4: 1-22.

88. Stults KR, Cummins RO. Fully automatic vs shock advisory defibrillators: what are the issues? J Emerg Med Serv 1987; 12: 71-3.
89. Wolfe DA, Kosinski D, Grubb BP. Update on implantable cardioverterdefibrillators - new, safer devices have led to changes in indications. Postgraduate Medicine 1998; 103: 115-30.

90. Cardiac Arrhytmia Suppression Trial (CAST) Investigators. Preliminary report: effect of encainide and flecainide on mortality in a randomized trial of arrhytmia suppression after myocardial infarction. N Engl J Med 1989; 321: 406-12.

91. Multicenter Automatic Defibrillator Implantation Trial (MADIT). Am J Cardiol 1997; 79(suppl 6A): 16-7.

92. Yee R, Klein GJ, Thakur RK. Clinical predictors of successful implantable cardioverter defibrillator implantation (part 2). Am Heart J 1994; 127: 1068-72.

93. Cardiac Arrest Study Hamburg (CASH). Meeting Highlights - 47th Annual Scientific Sessions of the American College of Cardiology. Circulation 1998; 97 2377-81.

94. Canadian Implantable Defibrillator Study (CIDS). Meeting Highlights - 47th Annual Scientific Sessions of the American College of Cardiology. Circulation 1998; 97: 2377-81. 